\title{
CONTRIBUIÇÃO AO ESTUDO DE MODELOS PARA CONTROLE DE GESTAO EM BANCOS DE ATACADO
}

\author{
Autor: Osias Santana de Brito \\ Mestre em Ciências Contábeis pela FEA/USP
}

Resumo para a defesa da dissertação apresentada à Faculdade de Economia. Administração e Contabilidade da Universidade de São Paulo (FEA/USP), como parte dos requisitos para a obtenção do título de mestre em Controladoria e Contabilidade em cumprimento à deliberação do Conselho do Departamento de Contabilidade e Atuária (CEAC), FEA/USP, em sessão de 14 de junho de 1993 nos padrões que visam a atender aos requisitos de aprovação editorial e de arbitragem, para publicação em revistas, jornais etc., conforme exigência do Departamento de Contabilidade e Atuária, a partir do segundo semestre de 1993.

\section{CONSIDERAÇÕES INICIAIS}

O Modelo de Controle de Gestão desenvolvido neste trabalho tem aplicação em instituições financeiras e, particularmente em bancos de atacado.

As instituições financeiras atuam em cenário que se apresenta dinâmico e fortemente regulado pelas autoridades monetárias.

Para obter melhor performance e posicionamento neste cenário, as instituições financeiras necessitam de instrumentos de gestão que lhes permitam conhecer seus pontos fortes e fracos.

O modelo de controle de gestão apresentado procura ajudar na identificação destes pontos fortes e fracos através da avaliação de desempenho e resultados e da avaliação dos riscos a que a instituição se expõe quando forma posições de descasamentos de indexador, moeda e prazo.

\section{Avaliação de Desempenho e Resultados}

Um modelo de avaliação de desempenho e resultados pode ser visto como integrante do planejamento e controle global da instituição, constituindo-se importante instrumento de gestão pelo qual a instituição pode identificar pontos fortes e fracos de sua atividade.

Funciona também como forma de acompanhar o orçamento, comparando o real com o previsto e possibilitando informações para correção dos desvios.

O modelo de avaliação de desempenho e resultados, objeto deste trabalho, é desenvolvido tendo como enfoque as análises por área, produto, gerente, cliente e agências. Por meio de abordagem divisional, é possível identificar suas contribuições ao resultado global da instituição.

Estas informações são fundamentais para gestão da instituição, pois ao identificar a origem de seus resultados, a forma como eles se constituem, os agentes que os formam, a instituição pode maximizá-los, redimensionando seus recursos e corrigindo desvios.

A distinção entre avaliação de desempenho e avaliação de resultados pode ser melhor compreendida através do trecho de notas de aula que transcrevemos abaixo: 
"avaliar desempenho significa avaliar ou mensurar a contribuição ou o resultado proporcionado á empresa, pelos seus respectivos centros de responsabilidade. Por outro lado, avaliar resultado significa avaliar ou mensurar a contribuição dos diferentes produtos operados na empresa para a formação do seu resultado global" 1

\section{Avaliação de Riscos de Descasamentos}

As instituições financeiras, costumeiramente, aplicam parte dos recursos captados junto ao mercado nacional e internacional (investidores) na formação de posições que envolvem riscos. Este trabalho se propõe a analisar não os riscos de crédito e sim os implícitos na volatilidade dos mercados em que a posição foi constituída. Se a instituição forma uma posição ao comprar ouro, estará sujeita à volatilidade da cotação ouro/grama.

Entendemos ser de fundamental importância a análise dos riscos de posição porque se apresentam freqüentemente nas operações dos bancos de atacado e, se não dimensionados e informados adequadamente à alta direção, podem ameaçar, inclusive, a continuidade da instituição.

\section{Caracterização e Importância do Objeto de Estudo}

Como forma de melhor caracterizar o objeto de estudo, entendemos importante descrever as características principais dos bancos de atacado. Os bancos de atacado, no Brasil, surgiram mais intensamente após a constituição de bancos múltiplos. Até então, se constituíam em bancos de investimento.

$\mathrm{O}$ advento do banco múltiplo possibilitou aos bancos operarem diversas carteiras com diversos tipos de operações sob uma mesma razão social. Até então, os conglomerados financeiros, eram constituídos de diversas empresas.

Os bancos de investimentos puderam operar carteira de banco comercial, "leasing", poupança, entre outras, sem a necessidade de constituição de novas empresas. Estes bancos começaram a se especializar, oferecendo a seus clientes opções que satisfizessem suas necessidades.

Caracterizados por tratar de um número reduzido de clientes com volumes monetários expressivos, os bancos de atacado especializaram-se em satisfazer as necessidades globais de seus clientes através de operações sofisticadas. É para este tipo de banco que pretendemos apresentar um modelo de controle de gestão.

Conhecendo os resultados que as áreas geram, quais os produtos mais rentáveis, quais seus melhores gerentes, quais seus melhores clientes, qual sua melhor agência e como gerenciar os riscos na formação de posição, este tipo de banco pode atuar melhor neste mercado altamente dinâmico e competitivo.

O conhecimento da composição de receitas e custos permite maximizar resultados, possibilita alocar esforços para obter a otimização no uso de recursos. Na formação de posição, consegue estimar perdas, não expondo sua continuidade ao risco.

Assim pretendemos com este trabalho apresentar pontos que entendemos importantes para controle de gestão neste tipo de banco.

1CATELLI, Armando - Notas de aula da cadeira "Contabilidade de Custos" do curso de Mestrado em Contabilidade e Controladoria - São Paulo, FEA/USP, Departamento de Contabilidade e Atuária. 1987.

Caderno de Estudos n¹1, São Paulo, FIPECAFI, Junho/1994 


\section{VISÃO GERAL DO MERCADO FINANCEIRO}

O Sistema Financeiro Nacional é constituído pelo Conselho Monetário Nacional, Banco Central do Brasil, Banco do Brasil, Banco Nacional de Desenvolvimento Econômico e Social e pelas demais instituições financeiras públicas e privadas.

\section{Estrutura do Sistema Financeiro Nacional}

\section{a. Conselho Monetário Nacional}

O Sistema Financeiro Nacional tem como órgão maior o Conselho Monetário Nacional, que traça as normas da política monetária em todos os seus aspectos, supervisionando também as políticas cambial, de investimento, de capital estrangeiro e comércio exterior.

Junto ao Conselho Monetário Nacional, funcionam Quatro importantes comissões consultivas: bancária, de mercado de capital, de crédito rural e de crédito industrial.

Além disso, três instituições operam diretamente ligadas ao Conselho Monetário Nacional: o Banco Central do Brasil, como agente executivo de suas decisões; o Banco do Brasil, na qualidade de principal órgão auxiliar de execução da política creditícia e financeira do governo; e o Banco Nacional de Desenvolvimento Econômico e Social (BNDES), como o mais importante agente governamental para a execução da política de crédito a médio e longos prazos. As demais instituições financeiras oficiais, ainda que sujeitas á disciplina do Conselho Monetário Nacional, possuem maior autonomia operacional.

Tais funções normativas e deliberativas são complementadas em sua execução, fiscalização e coordenação pelo Banco Central do Brasil através de seus departamentos técnicos e operativos.

\section{b. Podemos citar como demais instituições públicas e privadas:}

Comissão de Valores Mobiliários, Bolsa de Valores, Bancos de Desenvolvimentos Estaduais, Caixa Econômica Federal, Sociedades de Crédito Imobiliário, Sociedades de Crédito, Financiamento e Investimento, Sociedades Distribuidoras, Sociedades Corretoras, Agentes Autônomos de Investimento, Sociedades Arrendadoras e Sociedades de Investimento, Bancos Comerciais, Bancos de investimento e Bancos Múltiplos.

\section{Atuação dos Bancos de Atacado}

Os bancos de atacado diferenciam-se dos bancos de varejo por atuarem com reduzido número de clientes, reduzido número de agências (possuindo muitas vezes escritórios de representação ao invés destas), atendimento especial ao cliente, no sentido de lhe proporcionar alternativas de solução de seus problemas, oferecendo produtos diferenciados. Possui, geralmente reduzido número de funcionários, com menor estrutura administrativa, o que leva à redução de custos administrativos, comparativamente aos bancos de varejo.

Atuam no mesmo mercado financeiro que os bancos de varejo, porém com atenção voltada a clientes diferentes daqueles que os bancos de varejo transacionam. Os bancos de atacado, assim como os bancos de varejo, estão sujeitos à fiscalização do Banco Central do Brasil e as normas por ele emanadas. São obrigados a se enquadrar nos limites operacionais definidos pelo Banco Central do Brasil que tem por objetivo principal proteger o mercado financeiro de eventuais contingências que podem, principalmente, ser geradas por:

1. acentuada concentração de crédito em apenas um cliente. Se houver inadimplência deste cliente e não pagamento do empréstimo concedido, isto pode levar o banco ao não pagamento dos recursos captados;

Caderno de Estudos nº11, São Paulo, FIPECAFI, Junho/1994 
2. concentração de elevado volume de recursos em ativos cujos retornos são incertos;

3. excessiva concentração de investimentos em ativo permanente, diminuindo o capital de giro próprio do banco:

4. excessiva alavancagem Isto ocorre se o banco captar muitas vezes o equivalente ao seu patrimônio líquido e, na gestão inadequada da aplicação destes recursos, não obter resultados suficientes para o pagamento destes recursos captados.

Os limites operacionais se modificam com o passar do tempo, as entidades de classe, representantes do mercado financeiro, sugerem ao Banco Central do Brasil alterações para adaptar os limites operacionais a novas realidades de mercado.

Os limites operacionais procuram, ao restringir as operações no mercado financeiro, dar estabilidade ao mesmo, buscando evitar que os bancos ao operar sem limites, coloquem em risco este mercado.

\section{A Concorrência}

O mercado onde atuam os bancos de atacado se caracteriza por ser extremamente dinâmico. As decisões necessitam ser tomadas com agilidade e segurança. Como fatores que levam à diferenciação no mercado, destacamos:

\section{a. Aspectos relacionados com o quadro de pessoal}

\section{a.1 Aspectos motivacionais}

Um gestor motivado, geralmente, contribui melhor para que o banco atinja sua missão. Entre os fatores que levam á motivação, destacamos o programa de remuneração e o treinamento profissional.

O modelo de avaliação de desempenho e resultados procura evidenciar a performance do gestor. Ao saber como é avaliado, como são os critérios, e que sua melhor performance leva a uma melhor remuneração financeira, o gestor se motivará a melhorá-la. A discordância com relação aos critérios de avaliação deve ser discutida antes da realização das operações, pois se isto não for solucionado, o gestor pode não se sentir avaliado adequadamente e, portanto, não se motivar.

A alta administração tem papel fundamental nesta discussão, pois pontos divergentes sobre critérios de avaliação de gestores podem levar o modelo de avaliação de desempenho e resultados ao fracasso. Os "outputs do modelo não devem ser considerados isoladamente na avaliação do desempenho dos gestores". Também devem ser relevados outros pontos: visita de gerentes aos clientes e o grau de sucesso destas visitas, operações propostas aos clientes e operações obtidas, grau de eficiência da área financeira quando fornece o custo do dinheiro para a área que requisitou o recurso financeiro (isto ocorre quando determinada área solicita a área financeira captação de recursos e esta o capta mais caro ou mais barato do que a média do mercado),

\section{a.2 Grau de especialização}

Caderno de Estudos n¹1, São Paulo, FIPECAFI, Junho/1994 
Os profissionais deste mercado se caracterizam pelo elevado nível de especialização no negócio, conhecendo os detalhes que compõem os produtos e como oferecer aos clientes os produtos que melhor satisfazem suas necessidades.

Portanto, é fator diferenciador o treinamento do profissional destes bancos, de forma que o mesmo esteja atualizado com relação ao mercado e que também conheça os objetivos do banco em que atua.

\section{b. Formação de preço}

Os bancos de atacado, caracterizado por possuírem menor custo administrativo do que os bancos de varejo, apresentam preços diferentes para um mesmo produto.

Esta diferenciação se dá, basicamente, devido a:

\section{b. 1 Custo}

Certos bancos de atacado possuem custos administrativos inferiores a outros. Isto leva a possibilidade do banco oferecer taxa mais atraente ao cliente, já que o custo administrativo, parte relevante desta taxa, é inferior ao custo administrativo de outros bancos.

\section{b.2 Margem de rentabilidade}

Muitos bancos de atacado preferem reduzir a margem de rentabilidade da operação e conseguir a operação. Isto leva, geralmente, a um maior volume de negócios, reduzindo a margem de rentabilidade unitária e elevando a margem de rentabilidade global.

\section{c. Sistema de informação}

O banco de atacado que possui um sistema de informação com alta qualidade, consegue melhor se colocar no mercado frente à concorrência, pois um bom modelo de avaliação de desempenho e resultados, componente importante do sistema de informação, possibilita ao banco melhor conhecer a contribuição dos produtos ao resultado global da instituição, qual o gestor que melhor desempenha seu papel e como melhor utilizar sua capacidade.

O modelo de avaliação de riscos de descasamentos possibilita ao banco conhecer os retornos destes ativos, qual o melhor momento para desfazer a posição, que volume está exposto a riscos e qual a perda a que o banco está sujeito se mantiver a posição.

Os sistemas de orçamento e acompanhamento permitem, uma vez projetados os planos, verificar como estes estão se realizando e quais as correções necessárias para a consecução desses planos.

Com estas informações disponíveis, o banco pode inclusive, simular cenários, sempre se preocupando com o futuro, e como se posicionar ante as novas situações, como por exemplo, a queda da inflação. Decide melhor quais produtos podem deixar do operar e quais áreas podem ter seu quadro de pessoal reduzido numa eventual necessidade.

\section{CONCEITOS QUE ENVOLVEM O MODELO DE CONTROLE DE GESTÃO}

Os conceitos de sistemas, filosofia de uma empresa, sua missão, seus propósitos básicos, suas crenças e valores, seus objetivos, eficácia e eficiência, modelo de gestão, processo de planejamento e controle e sistemas de informações são muito importantes para a adequada utilização do modelo para controle de gestão proposto, ou seja, a compreensão dos outros problemas advindos do desenvolvimento, implantação e Caderno de Estudos nº11, São Paulo, FIPECAFI, Junho/1994 
manutenção do modelo de gestão e posterior à compreensão destes conceitos e suas interelações.

\section{ASPECTOS COMPORTAMENTAIS}

O modelo de avaliação de desempenho e resultados altera ou influência os aspectos comportamentais da instituição porque, o gestor ao saber que está sendo avaliado e, em decorrência desta avaliação, poderá ser recompensado ou punido, e quais os critérios que orientam esta avaliação, passa a manifestar maior ou menor motivação. O grau de motivação decorre da concordância ou não, pelo gestor, dos critérios de avaliação que serão observados.

Por isso, é fundamental que esses critérios, sejam avaliados e definidos harmoniosamente pela alta direção da instituição e pelos gestores, de forma a evitar atritos referentes à partilha de resultado entre gestores, o que pode levar o modelo de avaliação de desempenho ao fracasso.

A ineficiência de determinada área também não pode influir no resultado das outras áreas. Se, por exemplo, a área financeira capta o recurso muito acima do valor de mercado, a outra área que o requisitou não pode pagar por esta ineficiência.

É, portanto, necessário um acompanhamento permanente, por parte da controladoria, destas ocorrências, de forma a evitar que certas situações descaracterizem a utilidade maior do modelo da avaliação de desempenho e resultados, que é ajudar a instituição no atingimento de sua missão.

Há, porém, outros fatores a considerar na análise da performance dos gestores. além daqueles oferecidos pelo modelo de avaliação de desempenho e resultados. Um destes fatores é a análise do momento de mercado e se este possibilitou ao gestor realizar suas operações (sazonalidade de produtos). O outro fator relevante é considerar o número de visitas a clientes que foram feitas e o seu grau de sucesso.

O modelo de avaliação de desempenho e resultados não pode ser considerado como único mecanismo para avaliar a performance dos gestores. Devem ser levados em consideração outros aspectos que, juntamente com o modelo de avaliação de desempenho e resultados, levem aos gestores motivação para melhor desempenhar suas funções, de forma que os objetivos permanentes possam ser alcançados.

\section{PROPOSTA DE MODELO PARA CONTROLE DE GESTÃO}

O modelo de controle de gestão apresentado neste trabalho é constituído por um modelo de avaliação de desempenho e resultados e por um modelo de riscos de descasamentos aos quais a instituição se expõe quando forma posição no mercado financeiro. Os modelos de avaliação de desempenho e resultados e riscos de descasamentos se constituem em instrumentos de gestão integrada ao processo de planejamento e controle da instituição.

\section{Avaliação de Desempenho e Resultados}

A avaliação de desempenho e resultados que compõe este modelo parte da premissa básica de que os resultados gerados na instituição se formam através da participação de dois tipos de profissionais.

a. Gerentes de Produto: são os profissionais responsáveis pela elaboração e montagem do produto envolvendo análise dos seus aspectos básicos: formação de preço, viabilidade fiscal e jurídica do produto, distorção entre o tratamento contábil e o tratamento gerencial, entre outros; este profissional tem como função viabilizar o produto para a instituição, estando sempre atualizado com o mercado em que sua instituição atua.

Caderno de Estudos nº11, São Paulo, FIPECAFI, Junho/1994 
b. Gerentes de Cliente ou Gerentes Comerciais: são profissionais responsáveis pela venda do produto; a partir do momento em que o produto está disponível para a venda, estes profissionais devem oferecê-lo a seu cliente; representam o elo de ligação entre o cliente e a instituição.

Os resultados das operações gerados pelos gerentes de produto e pelos gerentes de cliente serão apresentados por:

- Área de negócios (centro de responsabilidade):

- Produto;

- Gerente de cliente ou gerente comercial.

- Cliente;

- Agência.

\subsection{Premissas para o desenvolvimento do modelo de avaliação de desempenho e resultados}

Para a aplicação do modelo, a instituição financeira deve possuir interesse em avaliar seus gestores através da performance de cada um, tendo em mente que será melhor remunerado aquele que mais contribuir para o resultado da instituição e não pensar em "socializar" parte ao resultado da instituição, ou seja, distribuir parte de seu resultado de forma homogênea entre seus funcionários.

O interesse em desenvolver o modelo para avaliar a performance de seus funcionários em relação ao resultado produzido por eles, individualmente, é atitude que deve estar contida nos planos da instituição, uma vez que se altera de forma significativa o comportamento de cada funcionário, pois ao sentir que será avaliado pela sua produção, ele tem interesse em maximizar seu resultado.

Um dos problemas que surge de imediato refere-se à partilha da receita ou ao preço de transferência. Isto ocorre porque o processo de geração do resultado de uma operação, geralmente, envolve a participação de mais de uma pessoa e mais de uma área. Será necessário definir o que cada área ou profissional envolvido levara do resultado da operação, qual será sua fatia. É neste aspecto que a direção da instituição deve estar ciente dos problemas que podem advir da partilha do resultado.

Determinado profissional pode sentir-se em desvantagem na divisão de determinado resultado e não fazer mais esta operação, desviando sua atenção para uma outra que the propicie maior percentual de participação. Porém, para a organização, esta outra operação pode não ser a mais interessante.

O modelo de avaliação de desempenho e resultados passa a ser também importante instrumento de planejamento estratégico, pois, ao incentivar maior participação do funcionário em determinado produto, pode atingir seu objetivo de vendê-lo mais. Exemplificando, se determinada instituição deseja incrementar sua participação no mercado de crédito, aumentando sua carteira de empréstimos, pode obtê-la dando ao gerente de cliente uma maior participação no "spread" obtido em cada operação. Se o objetivo maior da instituição é aumentar seu volume de captação, pode dar ao gerente responsável pelo produto referente à captação uma parte maior do "spread" obtido.

A premissa básica para que o modelo de avaliação de desempenho e resultados tenha sucesso é sua inserção no planejamento estratégico da instituição e sua divulgação a todos os interessados, destacando as razões pelas quais serão avaliados e a forma como isso ocorrerá.

A definição dos critérios de avaliação de desempenho e resultados deve passar por todos os envolvidos, de forma que saibam e compreendam os critérios avaliativos. Esse modelo é influenciado na sua constituição pelos aspectos culturais e comportamentais, pelas crenças. valores e políticas da instituição, pois é nesta conjuntura que o modelo de avaliação de desempenho e resultados será implementado. Quando da montagem do modelo,

Caderno de Estudos n¹1, São Paulo, FIPECAFI, Junho/1994 
este deve ser construído observando a forma da instituição atuar, como a instituição está organizada e como as responsabilidades são atribuídas.

O modelo de avaliação de desempenho e resultados tratará as informações produzidas pela forma da instituição operar. O modelo deve sempre se adaptar ao "modus operandi" da instituição. A atenção da alta direção para isto é fundamental, tendo em vista o interesse em se atingir sucesso na aplicação do modelo.

O modelo aqui proposto leva em consideração que a instituição financeira possui agências, tem claramente definidas suas áreas de negócios e de produtos, com nítida distinção entre elas, possuindo área administrativa independente das áreas de negócios e produtos. e que a instituição continuará existindo ao longo dos anos, sendo orientada a resultados.

A clara definição entre as áreas de negócios também chamadas de "força de vendas" e as áreas de produtos será de fundamental importância para distribuição do resultado obtido. O conceito referente a esta distinção refere-se ao caminho natural de realização de uma operação em que um gestor se responsabiliza pela elaboração de um produto (gerente de produto), possibilitando a força de vendas da instituição, composta de gestores responsáveis em identificar um cliente (gerentes de cliente), a venda deste produto.

\section{Modelo de Riscos de Descasamentos}

As instituições financeiras, e em particular, os bancos de atacado, constituem com muita freqüência posições expostas a riscos. Entendemos riscos neste trabalho, como a probabilidade de flutuações dos retornos dos ativos formados pelas posições em determinados mercados que se caracterizam por terem expressiva volatilidade. Como exemplo, podemos citar posições formadas no mercado de ações e mercado futuro.

Os bancos de atacado costumam formar posições nestes mercados porque o retorno financeiro que estas posições apresentam pode ser muito expressivo.

Devido às características destes mercados, reflexo da própria instabilidade econômica dos últimos anos, os bancos de atacado têm procurado maximizar seus ganhos, atuando cada vez mais intensamente na formação de posições sujeitas a riscos do descasamento, destacando-se:

a. Posições com riscos de indexador: estas posições são formadas quando a instituição financeira aplica determinado recurso em taxa pré-fixada ou pós-fixada, tendo captado este recurso em taxa pós-fixada ou pré-fixada

b. Posições com riscos de moeda: são formados quando a instituição financeira capta recursos em determinada moeda (dólar, por exemplo) e aplica estes recursos em outra moeda (cruzeiros, por exemplo);

e. Posições com risco de prazo: este tipo de posição é constituída quando a instituição capta determinado recurso por prazo diferente daquele em que aplica o recurso.

Os bancos, em geral, costumam operar posicionados em ativos cujos retornos estão sujeitos a intensas flutuações que derivam da situação econômica geral, medidas governamentais e instabilidades nos mercados nacional e internacional.

Nos últimos anos, os bancos têm concedido menos empréstimos em longo prazo para as indústrias, tendo direcionado este recurso para a constituição de carteiras cujos ativos apresentam retornos sujeitos a bruscas e intensas flutuações.

Torna-se, portanto, fundamental para o banco que forma estas posições de risco, constituir rigoroso controle sobre as mesmas a fim de resguardar de possíveis contingências.

Caderno de Estudos nº11, São Paulo, FIPECAFI, Junho/1994 
A elaboração de controle de avaliação destas posições é extremamente complexa, influenciando inclusive nos aspectos comportamentais dos profissionais envolvidos, pois estes deverão passar a operar segundo regras impostas.

\subsection{Composição dos Produtos em "Livros"}

Chamamos de "livro", neste trabalho, o agrupamento de operações que apresentam como característica comum o tipo de risco a que estão expostas (risco de indexador, moeda e prazo).

O primeiro ponto fundamental, então, é a separação dos diversos produtos (compostos de operações) em "livros", agrupados de acordo com suas particularidades.

Podemos, a princípio, trabalhar com os seguintes "livros", mais comuns nos bancos que operam com estas posições.

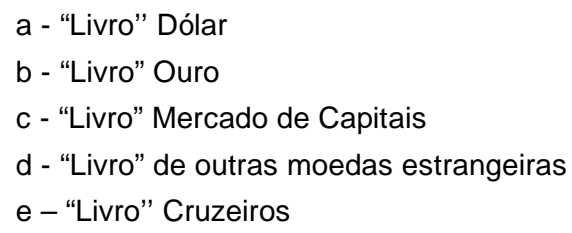

Se determinado banco trabalha com produtos que expressam risco de posição que não se enquadram nestes "livros" deve-se proceder á criação de outro "livro", sempre agregando os produtos que possuem características semelhantes quanto ao fator risco.

\subsection{Quantificação do Risco}

Após a separação e agrupamento das operações em "Livros", é muito importante a quantificação do risco a que o banco está exposto e a divulgação destas informações para a alta direção.

Para a quantificação do risco, devemos considerar:

a. os volumes envolvidos nas operações:

b. as taxas referentes a estas operações.

\section{O controle começa com}

a. comparação entre os limites de alçada delimitados por parte da alta direção referente a quanto cada operador pode formar posição, e qual o volume atingido por produto e "livro";

b. comparação entre as perdas a que o banco orçou (limite aceitável de perdas) para cada tipo de produto,. já definidos no orçamento, e o resultado real atingido através das operações efetuadas.

A análise de risco na formação de posições tem como objetivo principal demonstrar à alta administração como se encontram os níveis de exposição a riscos assumidos pelo banco por meio de posições próprias nos diversos mercados em que atua. Estes mercados são definidos em função dos indexadores que os regem,. ou seja, em função da intensa flutuação dos fatores de mercado aos quais as posições assumidas estão expostas. Alguns exemplos de fatores de mercado são o dólar, o ouro, mercado bursátil, entre outros.

Caderno de Estudos n¹1, São Paulo, FIPECAFI, Junho/1994 
Contribuição ao Estudo de Modelos para Controle de Gestão em Bancos de Atacado 10

Como mecanismo de controle, podemos destacar que se uma posição assumida exceder o limite de risco definido, uma das providências a seguir deve ser tomada:

- $\quad$ efetua-se urna revisão do limite risco definido de forma a adequá-lo à atual política de negócios do banco ou as atuais circunstâncias do mercado;

- $\quad$ reverte-se, parcialmente, a posição exposta a risco de forma a adequá-la ao limite préestabelecido.

O controle das posições de risco é fundamental para, junto com a avaliação de desempenho e resultados por área, produto, gerente, cliente e agência, possibilitar à alta direção informações importantes para que o banco atinja seus objetivos.

Ao saber quais posições estão expostas a risco, sua mensuração e a obediência aos limites definidos, alta direção tem como melhor decidir e evitar contingências.

Ao saber qual é a área que mais contribuí para o resultado do banco, qual é o melhor gerente, qual o produto que mas contribui para o lucro, qual o cliente mais rentável e qual sua melhor agência, o planejamento do banco ganha maior qualidade, possibilitando atuação mais eficaz num mercado tão dinâmico e competitivo.

\section{CONCLUSÕES}

Este trabalho teve como objetivo oferecer uma contribuição ao estudo de modelos do controle de gestão em bancos de atacado.

Procuramos mostrar que o controle de gestão em bancos de atacado pode ser materializado pela implementação de um modelo de avaliação de desempenho e resultados e um modelo de análise de operações que expõem o barco a riscos que necessitam ser evidenciados.

\section{As principais conclusões podem ser resumidas como segue.}

1. A condução de negócios em bancos de atacado é melhor efetuada se o banco utilizar avaliação de desempenho e resultados e avaliação de riscos de descasamentos. como ferramentas de gestão. Esta melhoria se dá porque.

a. A avaliação de desempenho e resultados possibilita á administração do banco conhecer como os gestores contribuem para a formação do resultado do banco e como os produtos participam de sua formação. Ao realizar tal identificação, o banco pode remanejar recursos de forma a maximizar seus resultados.

Para a implementação de um modelo de avaliação de desempenho e resultados, é fundamental que o banco esteja estruturado de forma divisional, com centros de responsabilidades e custos.

b. A avaliação de riscos de descasamentos possibilita ao banco conhecer a sua exposição a fatores de incerteza e gerenciá-los de forma a obter retorno desejado, controlando eventuais contingências. O risco discutido neste trabalho refere-se a risco na formação de posições em ativos, em mercados cujos indexadores se caracterizam por apresentar expressiva volatilidade. Não se trata, portanto, de análise de risco em operações de crédito.

Caderno de Estudos n¹1, São Paulo, FIPECAFI, Junho/1994 
Contribuição ao Estudo de Modelos para Controle de Gestão em Bancos de Atacado 11

O desconhecimento ou negligência em gerenciar posições de risco pode levar o banco a situações que afetam, inclusive, sua continuidade.

2. A elaboração de modelos de avaliação de desempenho e resultados e de riscos de descasamentos em bancos de atacado é necessária para suprir à alta administração com informações que subsidiarão decisões tendentes a tornar mais eficaz a atuação em mercados extremamente dinâmicos e de alta concorrência.

Por outro lado, ao saber que estão avaliados, e que receberão benefícios de acordo com sua performance mensurada pelo modelo, os gestores destes bancos terão sua postura modificada inclusive no que se refere a aspectos motivacionais.

3. Estruturação de modelos de avaliação de desempenho e resultados e análise de riscos em bancos de atacado diferencia-se daqueles elaborados em bancos de varejo por diversos fatores.

a. É possível, devido ao menor volume de operações que os bancos de atacado transacionem, analisar operação a operação diferentemente daquilo que ocorre com os bancos de varejo com elevado número de clientes e muitas agências; ao analisar operação a operação, ganha-se qualidade de informação, pois se trabalha com as características reais da operação.

b. Em geral, o tipo de operação efetuada pelos bancos de atacado possui maior grau de sofisticação em relação às efetuadas pelos bancos de varejo, que lidam com maior quantidade de clientes, e, geralmente, com volumes monetários menores.

c. Por terem estruturas menores e menor número de funcionários, a implantação de modelos de avaliação de desempenho e avaliação de riscos pode ser feitas de forma menos traumática em bancos de atacado Os problemas comportamentais nestes bancos, por ter menor número de funcionários, geralmente concentrados e não espalhados em agências, podem ter sua intensidade e complexidades melhor administradas.

d. Os sistemas de informação em bancos de atacado diferenciam-se dos bancos de varejo porque tratam um menor número de operações, evitam-se assim as dificuldades encontradas em bancos de varejo face ao grande número de negócios gerados.

4. Podemos destacar que alguns dos motivos que levam ao sucesso a aplicação do modelo de controle de gestão proposto neste trabalho:

\subsection{Referente ao modelo de avaliação de desempenho e resultados}

a. interesse da alta administração em utilizar as informações disponibilizadas pelo modelo para tomada de decisão.

b. interesse da alta administração em avaliar o desempenho dos gestores de acordo com sua performance.

c. capacidade da administração em resolver conflitos referentes à partilha do resultado entre as áreas ou gestores.

Caderno de Estudos n¹1, São Paulo, FIPECAFI, Junho/1994 
Contribuição ao Estudo de Modelos para Controle de Gestão em Bancos de Atacado 12

d. definição clara e amplamente discutida dos critérios referentes à partilha do resultado entre as áreas ou gestores envolvidos.

e. identificação e correção da influência de determinada área principalmente, quando esta eficiência implica no resultado de outra área.

f. utilização das informações que o modelo disponibiliza para, juntamente com outras análises, premiar ou punir os gestores: isto leva os gestores a participarem no resultado da instituição onde um resultado maior leva a uma premiação maior;

g. a alta administração deve analisar se a performance do gestor não foi prejudicada por fatores de mercado, como por exemplo, a sazonalidade de determinados produtos (caso do mercado bursátil); muitas vezes, o gestor não tem oportunidade de ter um desempenho melhor porque o mercado onde os produtos que gerencia são transacionados, não permite melhor performance;

h. se a alta administração resolver usar o modelo de avaliação de desempenho e resultados para atingir objetivos específicos para determinado período, repartindo o resultado das operações como forma de incentivar captação e administração de fundos, por exemplo, deve analisar estes efeitos, pois o gestor que ficou com a parte menor da partilha do resultado pode se desmotivar e individualizar interesses, em detrimento do interesse maior da instituição.

4.2. Referente ao modelo de riscos de descasamentos

a. interesse da alta administração em saber quais os volumes que estão expostos a riscos de descasamento,

b. conscientizar os gestores da importância do respeito a limites para formação de posições expostas a riscos de descasamento; geralmente, a vontade do gestor deste tipo de atividade é potencializar o ganho, muitas vezes se esquecendo que pode perder muito mais do que pode ganhar,

c. utilizar a relação retorno-risco como importante parâmetro para manter ou desfazer urna determinada posição em ativo;

5. Os modelos de avaliação de desempenho e resultados e de avaliação de riscos de descasamentos não surgem naturalmente, mas a partir de um processo de amadurecimento, no tempo, da própria instituição financeira, em termos de operações e de políticas de atuação. Necessitam, então, receber aprimoramentos ao longo do tempo, pois as operações e produtos transacionais sofrem modificações face ao mercado.

A implantação e manutenção destes modelos se dão, portanto, através de processos evolutivos que se aperfeiçoam continuamente.

Caderno de Estudos n¹1, São Paulo, FIPECAFI, Junho/1994 